\title{
Arranjos Neocorporativos e Defesa de Interesses do Médicos
}

\section{Neocorporatist Arrangements and Defense of Physicians' Interests}

\author{
José M. Ribeiro ${ }^{1}$
}

RIBEIRO, J. M. Neocorporatist A rrangements and Defense of Physicians' Interests. Cad. Saúde Públ., Rio de Janeiro, 9 (1): 05-20, jan/mar, 1993.

In B razil, the trade union structure created by authoritarian corporatism in the 1930's began to change when the cycle of the military regime installed in 1964 came to an end. With redemocratization, the trade union movement began to coexist with the organization of pluralistic interests, a process which has influenced the physicians' movement since 1977. The new National Constitution adopted in 1988 provided for multipartite control over health policy. We present a conceptual discussion of neocorporatist arrangements (which are common in European social experience) and their signficance for an understanding of health policy in the context of the so called Health R eform process in B razil.

Keywords: Neocorporatist Arrangements; Physicians; Health Policy

\section{INTRODUÇÃO}

A discussão acerca da representação funcional das diferentes categorias profissionais envolvidas no processo de trabalho em saúde é relevante para o estudo das políticas setoriais. Corporativismo é um termo vastamente empregado tanto no discurso das lideranças como no próprio debate acadêmico. Por ter seu uso vinculado a realidades bastante diversas ao longo da história, faz-se necessário enfrentar a questão conceitual como um pré-requisito para a sua utilização. Assim, esta dissertação se propõe a três objetivos que se complementam: 1. recuperar o conceito de corporativismo à luz de seus diferentes usos, buscando os elementos em comum que lhes dão sustentação ao longo da história; 2. detectar na literatura que envolve a formulação de políticas sociais em saúde os itens relevantes ao estudo da atuação dos atores sociais coletivos, com especial destaque aos médicos; e 3. discutir as formas tradicionais de vinculação entre organização de interesses e políticas públicas nos Estados capitalistas avançados, no sentido de extrair tendências relevantes ao caso brasileiro.

${ }^{1}$ Rua Visconde de Ouro Preto, 34, apto 602, 22250-000, Rio de Janeiro, RJ, Brasil.
Em vista da discussão teórica efetuada, propõe se o estudo de arranjos de caráter neocorporativo progressivamente presentes na formulação de políticas em saúde no Brasil. Tais arranjos constituem-se numa sólida tendência em desenvolvimento, onde os atores sociais coletivos, progressivamente organizados e conscientes de seus interesses perante o Estado e os demais setores sociais, passam a exercer, cotidianamente, as práticas de acordos em arenas cada vez mais compartilhadas e sob a égide do Estado.

Trata se de constatar que o corporativismo, no Brasil, é difundido, essencialmente, enquanto expressão de interesses "egoístas" e imediatos de categorias profissionais. Um outro uso freqüente do termo, também agregado à representação sindical, está na vinculação ao fascismo e, no Brasil, a toda a estrutura sindical historicamente assentada na legislação corporativa pós-30. O corporativismo, portanto, é uma presença constante e inevitável quando se fala em defesa de interesses em nosso país. Propomos, então, uma adequação do conceito, bem como a sua utilização prática em pesquisa, considerando as políticas sociais em saúde enquanto um território definido pelo Estado, no qual os atores sociais coletivos disputam bens e efetuam barganhas - cada vez mais estrutu- 
radas em arranjos duradouros de cunho neocorporativo - e cujo modelo gerencial do Sistema Único de Saúde emerge enquanto exemplo marcante e atual. Tais arranjos se apresentam apenas como mais um dentre os diversos mecanismos de tomada de decisões setoriais a serem estudados, tais como o papel da estrutura burocrática do Estado, os acessos privilegiados de grupos empresariais aos recursos sociais, a representação político partidária, etc.

O sindicalismo médico é utilizado como referência central em nossa discussão, em virtude do impacto que teve em certo período — a partir de 1977 — na incorporação dos médicos a experiências de defesa coletiva de interesses, com ressonância decisiva nas demais categorias profissionais da saúde, e pela prática de colocar-se perante a população, tentando vincular seus interesses imediatos a objetivos sociais mais amplos. Estas experiências estão no cerne da questão da representação funcional - desenvolver a capacidade de formular demandas coletivas de um segmento e convencer os demais quanto aos benefícios comuns de determinadas conquistas. Trata se de passar o próprio (demandas sindicais) pelo generalizado (melhorias nos serviços e na qualidade de vida).

\section{MOVIMENTO SINDICAL MÉDICO}

O papel do movimento sindical médico foi destacado em alguns estudos, sendo que consideramos dois deles como de maiores destaque e coerência interna. Com enfoques distintos, Campos (1988a) e Escorel (1987) buscam estabelecer as referências centrais do sindicalismo médico. Para Escorel, o movimento sindical médico, a partir das vitórias eleitorais do Movimento de Renovação Médica (Reme) ao final da década de 70, estabeleceu alianças e projetos conjuntos com outros setores da sociedade, extrapolando suas demandas exclusivamente corporativas. Tal ponto de vista considera que o movimento sindical médico chegou a se constituir numa das vertentes fundamentais da constituição do Movimento Sanitário em nosso país, que desembocou no projeto da Reforma Sanitária. Enquanto vertente, o sindicalismo médico seria um dos momentos da "constituição/ação" do Movimento Sanitário. Esta análise tem o mérito de captar uma certa articulação entre aspectos da prática sindical médica na conjuntura de transição política do país. Ou seja, avalia os mecanismos de construção de um determinado movimento de múltiplas origens profissionais a partir da atuação de setores dinâmicos presentes nas lutas sociais. Por outro lado, acreditamos ter ocorrido uma superestimação da adesão dos médicos a este processo. $\mathrm{Na}$ verdade, a incorporação da categoria aos princípios básicos das teses dos sanitaristas não ocorreu, tendo a mesma ficado restrita à atuação de lideranças politicamente engajadas via instâncias (como a organização partidária) cuja dinâmica operava por fora da base sindical. $\mathrm{O}$ Movimento Sanitário não foi fruto, enquanto um item crucial, do sindicalismo médico e de suas experiências cotidianas. Hoje fica mais fácil notar que não foram criadas bases sólidas dos projetos reformadores entre os médicos, embora naquela conjuntura tenha havido, isto sim, uma importante adesão de parcelas da categoria às reformas democráticas em nosso país.

O trabalho de Campos (1988a) segue um caminho diferente, enfocando, basicamente, as diferenças internas aos médicos, mesmo no que se refere às suas lutas corporativas. Embora movimentos coletivos tenham se repetido envolvendo segmentos distintos da categoria, estes não podem ser agrupados como uma corrente política única ou mesmo marcadamente dominante. Ao se buscar caracterizar as correntes políticas em atuação, remete-se não só a padrões ideológicos existentes, mas também a tipos diferenciados de inserção no mercado de trabalho que acabam por influenciar a prática política destes profissionais. As correntes políticas são construídas recorrendo se a certas bases materiais. O "kassabismo" (favorecido pelos médicos, em número cada vez menor, com maior controle de sua prática, dotados de elevada autonomia, representando os ideais liberais plenos na Medicina), o Reme (desenvolvido a partir das lutas sindicais envolvendo os assalariados e que, em certo momento, expandiu-se para a toda a estrutura representativa dos médi$\cos$ ) e o neoliberalismo (expressão da crescente associação entre consultório médico e convênio empresarial, responsável pela reatualização das aspirações liberais entre os médicos, carac- 
terizando um tipo de autonomia relativa) seriam correntes políticas portadoras de projetos diferenciados, todas mantendo algum grau de organicidade com a categoria, conforme assinala Campos.

Este modelo tem a vantagem de dar conta da profunda heterogeneidade da categoria, embora a progressiva mesclagem de vínculos profissionais leve a alguma convergência (médicos simultaneamente servindo como assalariados e em relação de autonomia relativa para viabilizar o projeto do consultório particular). Caso este processo de convergência mostre-se como uma tendência central, a construção de correntes políticas via mercado poderá perder a necessária nitidez. Neste sentido, apontamos, mais adiante, para a necessidade de se avançar nos estudos sobre a intermediação de interesses na saúde, a fim de detectar os mecanismos fundamentais pelos quais tais interesses se coletivizam e se transformam em projetos políticos e sociais.

\section{PRÁTICA MÉDICA E REFORMA SETORIAL}

O ideal de autonomia médica persiste enquanto a exteriorização de um exercício ótimo da Medicina (Schraiber, 1989). O fato dos médicos encararem seu processo de trabalho enquanto expressão de uma autonomia, vista como necessária e ideal, repercute na formulação dos interesses e na própria atitude perante o mercado. O assalariamento, visto como inevitável, traz consigo algo de contraditório no que restringe a soberania (pelo menos em parte) às custas da subordinação hierárquica e da nãodeterminação plena dos honorários. A autonomia pode, entretanto, ser destacada como persistente enquanto item geral. Isto é observado por diversos autores, que assinalam o papel do médico enquanto tomador de decisões nos sistemas sanitários como um todo (Bjorkman, 1988), ou pela sua capacidade de obstruir políticas públicas (Berlinguer, 1988).

Esta autonomia é vista por muitos como excessiva e danosa (Illich, 1975), estando a serviço de um sistema sanitário potencialmente iatrogênico, dispendioso e incapaz de promover benefícios na proporção dos recursos emprega- dos. O argumento de Illich se enfraquece, entretanto, ao negar a eficácia do ato médico em lidar com um conjunto de situações onde revela elevada resolutividade, como na assistência ao parto e ao perinatal, nas emergências, no controle de variados processos crônicos (diabetes, hipertensão arterial, neoplasias, etc). Seria ingênuo supor que o modelo assistencial médico industrial tivesse se tornado hegemônico sem conseguir dar respostas eficazes e imediatas a uma série de problemas. Tal constatação, no entanto, não invalida a questão central apontada por inúmeros autores - a de que o ato médico tornou-se progressivamente caro, invasivo e ineficaz em diversos aspectos da morbidade geral, e que a autonomia profissional tenha cursado com a expropriação de direitos e de atribuições dos indivíduos. Isto coloca ainda mais relevância na discussão acerca da autonomia profissional.

Segundo Donnangelo \& Pereira (1979), a discussão acima remete-se à politização do ato médico, onde os consumidores potenciais pressionam pela extensão dos benefícios da ciência médica, onde se contesta o gigantismo tecnológico e seus efeitos nocivos sobre os indivíduos, onde se nega a eficácia geral no prolongamento da vida das comunidades, e onde se assinala o caráter discriminatório na aplicação da tecnologia.

A organização dos interesses dos médicos tradicionalmente acompanhou o desenvolvimento da profissão. A formulação das demandas pelas diferentes associações, entre elas os sindicatos, respeita os cânones profissionais e tende a propalar a eficácia da Medicina, a necessidade da autonomia e a validade das conquistas tecnológicas. Tais elementos acabam reforçados pela própria sociedade, no dizer de Berlinguer cada vez menos tolerante à dor e às limitações da vida.

A politização da Medicina se expressa com particular ênfase em nosso país, especialmente na década de 80 , acompanhando o processo de redemocratização do país, no debate acerca das políticas públicas em saúde resumido em torno da Reforma Sanitária.

As ações em saúde consagradas na Conferência de Alma-Ata (1977), realçando os papéis dos serviços básicos, refletiram-se na VII Conferência Nacional de Saúde aqui realizada 
em 1980, onde ações integrando as políticas de âmbito federal com as estaduais e municipais passaram a expressar a combinação de algumas teses reformadoras, como a descentralização e a extensão de cobertura. Entretanto, foi com a VIII Conferência, realizada em 1986, em plena conjuntura de redemocratização política do país, que o projeto reformador ganhou impulso suficiente para influenciar a própria Assembléia Nacional Constituinte, em 1988. As teses centrais do Movimento Sanitário reformador caracterizaram-se pela reforma do Estado, enquanto instância capaz de redemocratizar, através de suas políticas, as relações sociais e suas desigualdades. As características dominantes da Reforma Sanitária foram, portanto, a promoção do acesso universal da população aos serviços; a descentralização gerencial, com o reforço dos papéis dos sistemas locais; a democratização da gestão dos recursos, através de estruturas tripartites (governos, usuários e profissionais de saúde); e a hierarquização dos serviços visando uma integração entre os diversos níveis de complexidade. No conjunto, uma determinação de que o Estado atue como o responsável primordial pela promoção da saúde da população.

Este processo desembocou na criação do Sistema Único de Saúde, onde ressaltamos como relevante à nossa discussão a gestão compartilhada de recursos e ações sanitárias, através de arranjos institucionais onde diferentes atores passam a disputar seus interesses, tendo que compartilhar consensos e conquistar determinados bens ou benefícios. Como veremos adiante, tal modelo admite as demandas funcionais em políticas setoriais e locais, caracterizando arranjos de caráter neocorporativo.

O movimento pela Reforma Sanitária apresentou-se aos médicos através de suas lideranças e teve ressonância, a nosso ver, especialmente por itens como a isonomia salarial entre os profissionais.

Enquanto movimento reformador do Estado, muitos foram os obstáculos que se apresentaram à sua viabilização. Alguns, fruto das condições objetivas envolvendo atores sociais; outros, decorrentes da própria proposta.

A começar pelo conteúdo básico da Reforma, Oliveira (1989) lembra que as proposições já estavam em curso há muito tempo, tendo ocor- rido apenas a constituição de um rótulo "altissonante" para dar coesão a itens que remontam à década de 60. Some-se a isto a literal transposição do modelo italiano, em que pese o fato das estratégias serem necessariamente distintas, em virtude dos atores sociais envolvidos. $\mathrm{Na}$ Itália, o movimento contou com uma base partidária e sindical mais sólida, que precedeu o longo debate parlamentar (Berlinguer, 1988). No Brasil, o peso da burocracia técnica sanitária na elaboração do projeto, aliado ao maior envolvimento de uma elite sindical cujas bases, como no caso dos médicos, estavam entre funcionários públicos, traz à tona uma forma particular do "pessoal de Estado" em levar adiante suas demandas corporativas: apresentar suas aspirações de expansão e reprodução enquanto anseios populares (King, 1988). A Reforma Sanitária fundamentou-se como uma reforma do Estado cujo eixo está na própria expansão do setor na saúde, o que condiz com os interesses de uma tecnoburocracia atuante e voltada para a sua reprodução.

Do lado dos movimentos sociais urbanos, é importante destacar a sua crescente demanda por serviços públicos. A lógica dos interesses coletivos não perpassa profissões como a Medicina, cujos rígidos vínculos corporativos determinam barreiras substantivas a qualquer processo reformador (Costa, 1989).

Tais obstáculos não esmoeceram o ímpeto dos formuladores da Reforma Sanitária em superar os limites corporativos. O movimento médico foi considerado por muitos como capaz de operar alianças históricas com o movimento popular (Teixeira, 1988). Tais expectativas estavam muito vinculadas ao próprio processo de redemocratização do país e à intensificação das lutas sindicais e políticas, gerando esperanças de que limites tradicionais da organização social brasileira pudessem ser superados ao longo do esvaziamento dos regimes militares. Os entraves, entretanto, foram se avolumando após as primeiras experiências gerenciais dos reformadores, constituindo-se num evidente dilema.

O dilema reformista estaria no fato da Reforma ter se desenhado em cima da crise do sistema, apresentando-se como alternativa em uma conjuntura peculiar (a "Nova República") onde o peso de forças políticas conservadoras 
no interior do aparelho governamental expôs seus formuladores à situação de gerir sem plenos poderes, levando a um desgaste da própria estratégia reformadora (Teixeira, 1988). Nesta altura, as diferenças com relação ao processo italiano já se apresentavam por demais claras. Entretanto, assinale-se, as teses básicas acabaram sendo acolhidas no texto da nova Constituição, pendente, obviamente, de regulamentação posterior.

Os limites, no entanto, não estariam apenas no equilíbrio de forças no governo. O processo de articulações "por cima" privilegiado pelos reformadores, com todas as suas conseqüências, não levou em consideração o peso decisivo do mercado em condicionar e distribuir recursos de origem pública (Campos, 1988b). Conforme lembra Campos, entre outros, o Instituto Nacional de Assistência Médica e Previdência Social (Inamps) e diversos fundos públicos bancaram a mercantilização da assistência médica em nosso país. O peso do mercado na área da saúde surge como um evidente elemento de condicionamento da atuação dos atores sociais. No caso dos médicos, quaisquer reformas terão que levar em conta os meios como se organizam e expressam interesses, tendo o mercado como fonte de demandas que não podem ser tomadas, a priori, como conversíveis aos interesses coletivos. A contínua expansão dos serviços privados em saúde em nosso país (Favaret-Filho \& Oliveira, 1989) enfraquece uma das mais caras expectativas dos reformadores: a subordinação de amplas camadas da medicina privada à lógica do Estado.

\section{CORPORATIVISMO E ESTADO}

O corporativismo tem sido descrito a partir de pontos de vista variados. Além disso, tornou-se senso comum vinculá-lo aos processos de defesa de interesses imediatos de categoriais funcionais. Outra base empírica encontra-se nas políticas de Estado, como o fascismo, e em diversos mecanismos de cooptação de lideranças sindicais no sentido de torná-las cooperativas com políticas governamentais. Deste modo, torna se importante uma precisão teórica do que seja corporativismo e as formas como este influencia a organização política e social brasileira.

O fundamento básico do corporativismo encontra se no fato de atividades profissionais se organizarem em associações de interesses coletivos (corporações). Tal doutrina "propõe, graças à solidariedade orgânica dos interesses concretos e às formas de colaboração que podem daí derivar, a remoção ou neutralização dos elementos em conflito" (Incisa, 1986). Tal definição, embora vinculada a regimes autoritários, guarda dois aspectos que persistem como fundamentos do que hoje é definido como neocorporativismo: a solidariedade interna de grupos profissionais e a intervenção do Estado demarcando o processo de redução do conflito.

O desenvolvimento das forças produtivas no capitalismo interferiu na organização corporativa por ofícios, subvertendo o modelo tradicional (Marx \& Engels, 1982). Isto nos obriga a distinguir entre as prescrições corporativas católicas (vinculadas a um comunitarismo destruído pelo capitalismo) e o corporativismo dos Estados autoritários que acompanharam o processo de acumulação de capital em sociedades como a brasileira (Vianna, 1976). Ou seja, mudanças nos modos de produção ou de regimes imprimem características próprias à organização corporativa.

Ainda no campo conceitual e ligado às práticas sindicais, deve-se ressaltar o debate de Lenin (1973) com o que denominou economicismo (apontado como uma tentativa de afastar das lutas sindicais a colocação de alternativas de organização política do Estado, acreditando que, espontaneamente, pelas experiências cotidianas, os proletários chegariam à ruptura com o Estado burguês). Lenin assinala que, pela via das lutas econômicas, os trabalhadores não superariam níveis "trade-unionistas" de lutas sociais. Assim, trava embate com estratégias de caráter corporativo no interior da esquerda, embate este que vai influenciar toda a atuação posterior da esquerda marxista, inclusive no Brasil.

O corporativismo aparece, portanto, como mecanismo de regulação para o Estado e como entrave estrutural para a esquerda marxista. Para o marxismo, o processo de conscientização das classes dominadas é crucial. Gramsci 
(1978) define como catarse "a passagem do momento puramente econômico (ou egoísta-passional) ao momento ético-político, isto é, a elaboração superior da estrutura em super-estrutura na consciência dos homens".

Não devemos, no entanto, atribuir às estruturas corporativas o único papel na viabilização da crescente hegemonia burguesa (e, com ela, o desenvolvimento do capitalismo). Segundo Gramsci (1968), elementos não-organizados, como os intelectuais, desempenharam papel de destaque. Dentre estes, os médicos são vistos como intelectuais tradicionais e alvo de políticas de cooptação da parte da nova classe burguesa, no sentido de atuarem como veiculadores de novos valores. Os médicos, assim como juristas e eclesiásticos, para Gramsci, tendem a procurar ocupar espaços ideológicos acima das classes fundamentais, embora o seu progressivo papel subordinado na nova sociedade capitalista não tenha sido esquecido por Marx \& Engels no próprio Manifesto Comunista, ainda nos primórdios da construção de uma esquerda que influenciou decisivamente o movimento sindical em todo o mundo. Neste caso, buscava-se ressaltar o violento e acelerado processo de conformação das estruturas e atores sociais à lógica do capitalismo em desenvolvimento.

O Estado capitalista desenvolveu relações com atores coletivos, com especial atenção às práticas do movimento sindical operário. Para Panitch (1981), o corporativismo emerge como uma estrutura do capitalismo avançado, "que integra grupos produtivos, organizados através de um sistema de interação mútua, de representação e cooperação ao nível das lideranças, e de mobilização e controle social ao nível das massas". Trata-se, obviamente, de uma visão pessimista quanto a tal modelo de intermediação de interesses. A gestão por parte dos sindicatos de parcelas do poder não seria suficiente para que tal modelo deixasse de ser "funcional" ao sistema. A social-democracia moderna aparece como patrocinadora, na Europa, de experiências corporativas, cabendo ressaltar que o conceito de corporativismo tradicional implica o controle do Estado sobre a representação funcional e a defesa fragmentada de interesses ao nível das profissões. Tais características permaneceram nos modelos neocor- porativos, acrescidas da sistemática democrática especialmente expressa pela autonomia das organizações de interesses em assuntos internos. Os modelos neocorporati-vos, aliás, embora surgidos pelas mãos dos sociais-democratas, persistiram em governos conservadores (Przeworski, 1989).

Portanto, a relação entre corporativismo e Estado, que remonta à própria construção do capitalismo, retorna (como será assinalado por Schmitter, 1974) no capitalismo avançado com peculiariadades que o diferenciam do antigo modelo dirigista, do qual o fascismo foi uma expressão típica.

O Brasil e outros países latino-americanos caracterizaram-se por modelos corporativos diferenciados. Segundo O’Donnel (1976), "sociedades diversas, corporativismos diversos". Na América Latina, segundo este autor, o padrão de Estado burocrático-autoritário (que sucedeu, pela via militar, os governos populistas em decomposição) refletiu-se no próprio tipo de corporativismo. O "corporativismo bifronte" seria expresso pela convivência entre o componente estatizante (subordinação ao Estado de organizações da sociedade civil) e o privatista (abertura de áreas do Estado à representação de interesses presentes na sociedade civil). Trata-se, portanto, de assinalar a permanência de padrões corporativos em países como o Brasil, sem excluir outros modos de representação de interesses e sem se prender ao modelo dirigista (estatizante) oriundo do período varguista pós-30.

Para assinalar a complexidade da organização política em nosso país, vale enfatizar que o processo de cooptação pelo Estado guarda características freqüentemente classificadas como pertencentes a uma relação patrimonialista entre sociedade e Estado. Como assinala Schwartzman (1988), "o estamento burocrático brasileiro é permissivo e incorpora, com facilidade, intelectuais, empresários, líderes religiosos e dirigentes sindicais". Delineia-se, deste modo, uma corporativização da vida nacional com o Estado, através do seu estamento burocrático, atuando no enquadramento das associações que se destaquem por uma atuação mais dinâmica.

Para dar conta de tamanha variedade, como a 
aqui lembrada, Schmitter (1974), através de um trabalho clássico, procurou, recorrendo à construção de modelos típicos-ideais, destacar os diferentes tipos de corporativismo, segundo grupos de nações. Para tanto, partiu, inicialmente, de uma definição do que seria o modelo corporativo típico-ideal e deu origem a toda uma escola acadêmica que passou a ser reconhecida pelos estudos sobre modelos neocorporativos. Procurando destacar o corporativismo como uma das possibilidades de representação de interesses em sociedades modernas, dentre as quais o pluralismo despontava como a mais reconhecida, assinalou Schmitter que "corporativismo pode ser definido como um sistema de representação de interesses no qual as unidades componentes são organizadas em número limitado, de caráter singular, compulsório, não-competitivo, reconhecido ou concedido (senão criado) pelo Estado, e portadoras de monopólio representativo deliberado em suas respectivas categorias, em troca da observação de certos controles na sua escolha de lideranças e articulação de demandas e sustento".

Para acomodar países distintos, como o Brasil e a Suécia, entre os sistemas corporativos, recorre à subdivisão em dois tipos: um mais autônomo e penetrante (corporativismo societário), e outro dependente e penetrado (corporativismo de Estado). Ao aplicar tais modelos ao estudo de diferentes nações, observa que tais não configuram exemplos "puros", mas sim padrões dinâmicos em cima dos quais se desenvolveram as formas corporativas. O corporativismo societário mostrou-se concomitante ao Estado de Bem-estar Social do capitalismo avançado, emquanto o corporativismo de Estado emergiu como uma necessidade estrutural do Estado capitalista atrasado. Na verdade, observa se que o corporativismo societário nasceu do declínio lento, mas seguro, do pluralismo preexistente, ao passo que o corporativismo de Estado emergiu a partir da morte prematura e rápida de um pluralismo nascente, como ressalta.

O Brasil encaixa-se no que Schmitter assinala como corporativismo de Estado, e as relações históricas deste modelo com o sindicalismo brasileiro foram bem desenvolvidas por Vianna (1976).

\section{SINDICALISMO E CORPORATIVISMO NO BRASIL}

A associação habitualmente feita no Brasil entre sindicalismo e corporativismo torna-se evidente a partir da década de 30, ao longo da construção do Estado Novo de Getúlio Vargas. Foi neste período que a Legislação Trabalhista e o próprio Estado adquiriram, de modo progressivo, feições corporativas que influenciaram a acumulação de capital no país. No Brasil, os anos 30 são referências essenciais para o entendimento do movimento sindical e das leis trabalhistas, que são, até hoje, imbuídas de tal herança.

O estudo de Vianna (1976) sobre este assunto é profundo e abrangente, fornecendo uma interpretação bem particular para o processo de identificação da burguesia industrial da época com o Estado corporativo. Assinala o modo como ocorreu a transposição do projeto liberal - fordista da burguesia industrial (obstaculizado pelas condições vigentes no país) rumo à estratégia de forte participação do Estado nas relações mercantis e sociais. Chama também a atenção para o papel modernizador desta burguesia industrial, construindo a sua hegemonia, de forma lenta e molecular, junto às demais facções burguesas (como os setores agrário-exportadores). O peso que a transformação dos sindicatos livres nascentes em estruturas oficiais teve no processo de acumulação explica, em parte, a longa duração da legislação sindical corporativa em nosso país.

O fracasso do modelo liberal fordista no Brasil deu-se em meio a uma crise de hegemonia, e o corporativismo (com leis e estruturas características) surge como a via de modernização autoritária adotada no país. O paradoxo do abandono do liberalismo característico de países de capitalismo originário (que seria a forma "vocacional natural" da burguesia) e da adoção do Estado forte nos anos 30 só é entendido através dos obstáculos enfrentados pela nova burguesia em enquadrar os trabalhadores através da "educação pelas fábricas" para a obtenção do consenso.

Neste sentido, o Estado entrou nas relações trabalhistas buscando fortalecer o sindicalismo oficial, criado por legislação da época e submetido a diversas limitações quanto à sua 
autonomia interna e práticas reivindicatórias. $\mathrm{O}$ florescimento de um sindicalismo livre e autônomo, desde o início do século XX, no Brasil, foi enfrentado pelo Estado através da repressão política, associada a crescentes incentivos seletivos ao sindicalismo oficial (assistência médica por convênios oficiais, financiamento a associados, imposto sindical, etc).

A estrutura sindical corporativa, segundo Erickson (1979), deixou de cumprir seu papel amortecedor de tensões sociais no início dos anos 60. O "trabalhismo radical" foi enfrentado pelos militares no golpe de 1964. Estes, às custas da repressão política, reforçaram as amarras ao sindicalismo engendradas pela legislação corporativa. Esta foi mantida ao longo dos regimes militares, para ser questionada, de modo incisivo, a partir de 1977, com a retomada das lutas sindicais maciças e a emergência do chamado sindicalismo autêntico, que buscou livrar-se da custódia do Estado.

\section{NEOCORPORATIVISMO E POLÍTICAS SOCIAIS}

O conceito de neocorporativismo nos parece bastante útil ao entendimento das relações entre o Estado capitalista e os atores sociais organizados. Tais arranjos foram desenvolvidos em diversos países da Europa, observando-se uma influência marcante de sindicatos operários em políticas de rendas, de trabalhadores em serviços públicos na elaboração das políticas sociais, e um conjunto complexo de relações sociais que não podem ser reduzidas ao modo clássico de pensar o corporativismo, tendo em vista a convivência entre a intervenção do Estado e um certo pluralismo na representação funcional. Nosso interesse, no momento, não reside no estudo do neocorporativismo enquanto um possível paradigma nas Ciências Sociais. Nos interessa apreender os mecanismos de interferência de atores coletivos nas políticas públicas e a do Estado nos processos de elaboração de interesses observados na sociedade. Isto em decorrência da necessidade, a nosso ver, de que os marcos teóricos das pesquisas sociais no Brasil assimilem a tendência aqui observada de que arranjos de caráter neocorporativo se apresentem cada vez mais nos cenários local, setorial e, menos nitidamente, nacional.

A distinção entre os diversos enfoques acerca do corporativismo se faz necessária. Para Regini (1986), "a diferença fundamental é a seguinte: num sistema neocorporativo, a organização representativa dos interesses particulares é livre para aceitar ou não suas relações com o Estado, contribuindo, portanto, para definí-las, enquanto no corporativismo clássico é o próprio Estado que impõe e define estas relações".

O Estado capitalista avançado é o território privilegiado para a discussão conceitual por nele conviverem, há longo tempo, políticas sociais desenvolvidas e sólidas organizações sindicais. Para Offe \& Ronge (1987), tal Estado não pode ser reduzido a um mero instrumento de uma classe específica ou mesmo de segmentos sociais. “...o Estado não defende os interesses particulares de uma classe, mas sim os interesses comuns de todos os membros de uma sociedade capitalista de classe". Tal defesa não pode, entretanto, ser confundida com uma utopia democrática. Dar conta de interesses comuns é a expressão da necessária legitimação deste Estado. A referência ao modo de produção capitalista define o caráter das estratégias a serem desenvolvidas. Como assinalam, “...nossa tese consiste em afirmar que existe uma, e somente uma, estratégia geral de ação do Estado. Ela consiste em criar as condições segundo as quais cada cidadão é incluído nas relações de troca". Tais relações de troca implicam a caracterização do indivíduo na forma mercadoria, pela venda de sua força de trabalho, sendo esta forma-mercadoria o "elo entre as estruturas políticas e as econômicas".

As estratégias básicas de reprodução da forma-mercadoria seriam, de um lado, o automatismo de mercado (que pressupõe uma reincorporação posterior das unidades de valor seletivamente excluídas da forma-mercadoria através do balanço oferta/demanda), e, do outro, as políticas estatais de preservação das unidades de valor segundo políticas anti-cíclicas (keynesianas). Tais estratégias apresentam contradições significativas: a primeira, pelo desequilíbrio na força de trabalho decorrente de demissões não acompanhadas de ressocialização imediata; a segunda, pelos crescentes gastos 
fiscais em políticas públicas. Offe \& Ronge delineiam uma terceira via em andamento na Europa Ocidental, baseada em três itens: programas de reciclagem profissional, visando aumentar a capacidade de troca da força de trabalho; aceleração da capacidade de troca de bens de capital via integração supranacional de mercados e diversas políticas nacionais e regionais de pesquisa e desenvolvimento; e "saneamento planejado" de segmentos da produção atrasados quanto à sua capacidade de rápida produção e circulação de bens.

Tais estratégias pressupõem um ampla interferência do Estado nas relações de troca e na relação entre os interesses sociais organizados. Isto revela um Estado organizador do processo econômico e interessado na ação dos atores sociais.

Algumas contradições fundamentais emergem do quadro descrito. Uma delas estaria em que o Estado, para viabilizar a reprodução da forma-mercadoria (de cuja atuação depende a sua própria sobrevivência via recolhimento de impostos, etc.), lança mão de políticas que pressupõem o crescimento da força de trabalho em serviços empregada nas próprias agências estatais. Tais segmentos sociais estariam distante de se comportarem pela lógica da mercantilização. Seus referenciais de produção seriam distintos daqueles presentes na esfera mercantil plena. Desta maneira, haveria uma desmercantilização da força de trabalho a serviço da reprodução desta enquanto mercadoria. Como assinala Offe (1982), "do meu modo de ver, esta relação entre welfare e capitalismo é contraditória: sob as condições de capitalismo moderno, uma estrutura de apoio de instituições não-mercantilizadas é necessária para um sistema econômico que utiliza a força de trabaIho como se fosse uma mercadoria". O crescimento do setor de serviços na rede pública seria, então, um subproduto "não-funcional" da expansão capitalista.

\section{A REPRESENTAÇÃO DE INTERESSES E O NEOCORPORATIVISMO}

A representação de interesses não se dá apenas pela vontade dos indivíduos representados, mas atende a um complexo mecanismo que vai desde a própria elaboração de quais demandas são relevantes e plausíveis, passando pela capacidade de tais demandas homogeneizarem, mesmo que apenas por um instante, os indivíduos em torno de seus representantes, até chegar ao papel que as instituições públicas desempenham no sentido de torná-las aceitáveis ou não, ou mesmo de reconhecerem seus interlocutores.

A formação e a atuação de grupos de interesses, segundo Offe (1989a), dependem de três pontos: da vontade e identidade coletiva do grupo; da "estrutura de oportunidades" sócio-econômica; e das práticas institucionais proporcionadas pelo sistema político a estes grupos, na forma de "status público". O autor critica a teoria pluralista por estar demasiado presa à expressão das vontades individuais. Assinala Offe: "A forma e o conteúdo concretos da representação de interesses organizada é sempre um resultado do interesse, mais a oportunidade, mais o status institucional".

O Estado aparece como força interferente na intermediação de interesses. O status público, positivo ou negativo, atribuído via incentivos ou sanções, estimula ou cerceia interlocutores, voltando-se para a estratégia final de redução do conflito global da sociedade. Na verdade, não ocorre uma redução do conflito, mas uma fragmentação destes ao longo da sociedade. $\mathrm{O}$ status público atribuído às organizações de interesses é considerado por Offe um item crucial na intermediação de interesses na sociedade.

A representação funcional (neocorporativa) emerge como adaptada ao desenvolvimento capitalista e capaz de dar conta de itens variados, os quais incluem o papel de selecionar questões que sirvam de informação global ao sistema, sem a sobrecarga de demanda que a representação partidária tende a oferecer. A agenda política da social-democracia européia na década de 60 já dava sinais de sobrecarga devido às políticas de crescente proteção social, fazendo com que os modelos neocorporativos se desenvolvessem, em países como a Alemanha Ocidental, em cima do enfraquecimento do sistema de representação territorial assegurado pelos partidos políticos. Poder-se-ia dizer que a representação funcional neocorporativa desenvolveu-se junto com uma certa degeneração do 
sistema de representação partidária (perda de identidade dos partidos, sobrecarga de demandas, etc.). Uma síntese de tal processo e das mudanças no conceito de corporativismo é encontrada em Offe (1989a): "Essa dupla natureza do corporativismo é essencial: implica restrições impostas à base de poder de grupos, assim como um ganho em termos de autonomia. Significa etatisation da política de grupos em um caso e 'promessa de não-interferência' do poder do Estado no outro...0 aspecto característico do corporativismo moderno, em contraste com os modelos autoritários, é a coexistência de dois circuitos, havendo uma substituição apenas limitada da representação territorial pela representação funcional".

No rastro de certo esvaziamento da representação partidária, o modelo neocorporativo não se apresenta como estável ou necessariamente persistente, mas como uma instância adicional aos modos de representação de interesses que pode ter seu alcance aumentado ou diminuído conforme elementos conjunturais de cada região ou setor. A despolitização do cotidiano, implementada pela ação do Estado, soma-se à fragmentação do conflito como uma das "vantagens" do modelo em termos de estabilização dos processos sociais. No entanto, como assinala Offe, tal modelo está longe de ser estável, pois carrega também um certo grau de imponderabilidade. Seria também um modelo frágil devido às suas contradições. A estabilização do modelo corporativo depende de sua capacidade de "pressupor o consenso" e de uma aceitação incontestável do método de aceitação/exclusão de organizações e dos resultados alcançados, o que está longe de constituirse numa garantia absoluta. Outro aspecto é a intensificação do conflito politico não-institucional, ou seja, a possibilidade de que grupos voltados a temas extra-sindicais (questão urbana, defesa ambiental, etc.) ou de que se rompa o mecanismo tradicional de colaboração entre elites sindicais, com o fortalecimento de lideranças que denunciem o caráter do pacto de classes implícito no neocorporativismo.

Um outro cenário, menos factível, consistiria "na correção do viés de classe do corporativismo". Tal se daria em virtude de um magnífico aumento do poder de barganha dos trabalhadores, dotados de sindicatos cada vez mais fortes e organizados, forçando a um deslocamento do centro de poder para os organismos paritários, com a subordinação das outras partes aos desígnios do movimento social organizado. Tal possibilidade é vista com bastante desconfiança também por autores como Panitch (1981), que ressalta o forte elemento de colaboração embutido no desenvolvimento do corporativismo, e Przeworski (1989), que descreve as "bases materiais" onde se estabelece o consentimento dos trabalhadores com as regras do jogo do modelo capitalista, dos quais são reféns (perdem com a crise do sistema e não têm garantias efetivas de ganhos proporcionais decorrentes da superação das crises econômicas).

Para Offe, o modelo neocorporativo tem seu equilíbrio tendendo ao fortalecimento das posições burguesas. Os trabalhadores tendem a ser mais comprometidos com os acordos decorrentes dos organismos tripartites do que os empresários. Para estes, as tomadas de decisões, em termos de investimentos e de itens que dizem respeito ao processo de acumulação e reprodução do capital, passam basicamente por canais diversos dos comitês, sendo que seus representantes não podem assegurar o mesmo grau de solidariedade de seus pares como o observado entre os sindicatos operários. Para os sindicatos dos trabalhadores industriais, a centralização cada vez maior torna-se uma necessidade para enfrentar grupos econômicos cada vez mais abrangentes, o que compromete itens como a autonomia das entidades de base (Wallerstein, 1989).

\section{DEMOCRACIA E POLÍTICAS DE PROTEÇÃO SOCIAL}

A questão democrática surge acompanhando a representação de interesses na sociedade. Ela envolve a defesa coletiva e individual de interesses perante o Estado e entre os próprios segmentos sociais. O Estado de Bem-Estar Social, como desenvolvido em países da Europa Ocidental, foi constituído em cima de alguns parâmetros importantes: democracia política, densidade eleitoral da esquerda social-democrata, políticas econômicas inicialmente de caráter anticíclico (keynesianas), formulação de políti- 
cas sociais redistributivas pelo Estado e de proteção individual. Em tais contextos, a participação dos sindicatos de trabalhadores, com destaque para o setor industrial e as grandes centrais sindicais, desempenhou um papel importante, chegando, em determinados momentos, a parcerias de caráter co-gestionário. Desta forma, o neocorporativismo, tanto em sua expressão geral nos grandes acordos nacionais como em suas dimensões setoriais ou locais, apresentou-se enquanto elemento freqüentemente associado ao Estado de Bem-Estar.

Uma questão está nos possíveis limites redistributivos e protecionistas desta convivência entre Estado e atores sociais coletivos. Afora a constatação do caráter de classe burguês dos modelos neocorporativos, há também todo o debate que envolve a própria crise do padrão "welfariano" desde a década de 70, a qual originou, nos anos 80, o vendaval neoliberal, colocando as estratégias sociais-democratas (dependentes fundamentalmente do Estado) em dúvida quanto à sua capacidade de agregar justiça social com desenvolvimento econômico sob a égide de políticas públicas.

Neste universo emerge a pergunta feita por Offe (1989b): Seria o Estado de Bem-Estar Social uma decorrência natural e necessária da progressiva democracia política? Surpreendentemente, Offe detecta mecanismos onde a escolha individual, freqüentementemente anônima através do voto em eleições, atua no sentido de influenciar o desmonte de estruturas de proteção social. Para este autor, democracia e welfare não se alimentam mutuamente, e ele assinala o enfraquecimento do "estatismo centrado no trabalho" (onde indivíduos atuariam em função de solidariedades determinadas funcionalmente, esperando-se comportamentos eleitorais de uma maioria de trabalhadores em favor do welfare state) e da hipótese de auto-reprodução institucional do modelo (os bens proporcionados pelo Estado de Bem-Estar gerariam um consenso que bloquearia possíveis iniciativas restritivas dos benefícios da parte de partidos conservadores).

Considera Offe que tais pressupostos não se sustentam à luz da experiência européia dos anos 80, onde pode-se alinhar: derrotas eleitorais de socialistas e sociais-democratas, contínuas, perante partidos conservadores portadores de discursos anti-welfare state; interrupção dos gastos em políticas de bem-estar social e declínio em participações orçamentárias; ausência de esforço militante no interior da sociedade em favor de tais políticas; desserção eleitoral de núcleos expressivos das classes trabalhadoras em favor de liberais-conservadores; fortalecimento de movimentos sociais não vinculados a classes sociais, como pacifistas, ambientalistas, etc.

Segundo Offe, ítens como a carga fiscal, a crítica ao "paternalismo" de políticas de auxílio desemprego e a mudança do perfil ideológico de segmentos formadores de opiniões, no sentido de avaliar como negativo o peso excessivo de Estado, debilitaram o consenso em torno do Estado de Bem-Estar Social. A relação dos indivíduos com a "coisa pública" passa a merecer especial atenção. Na democracia, o custo da recusa é zero para o indivíduo (o nãoeleitoral), o que estimula a que cada um efetue cálculos no sentido de maximizar seus ganhos, na ausência de constrangimentos coletivos. A mudança nas estruturas de oportunidades em sociedade (com a intensificação da tecnologia, a diversidade profissional, os ganhos econômicos de trabalhadores na esfera industrial, etc.) seria a base para uma certa decomposição individualista dos modelos neocorporativos baseados na ação coletiva solidária.

Os agentes individuais, assim, passam a medir seus ganhos específicos com cada bem público produzido e, além disso, na ausência de incentivos ideológicos ou de sanções, omitem-se nas contribuições à produção de determinados bens sociais, mesmo estando de acordo com os mesmos.

Desenha se, deste modo, um quadro onde cada agente individual atua de acordo com uma lógica de maximização dos ganhos, o que é condizente com valores do liberalismo, onde a obtenção do máximo por cada um serve de alavanca para o desenvolvimento da sociedade.

Claro está que os padrões de democracia partidária, arranjos neocorporativos e ação individual decorrente da maximização de ganhos convivem nas sociedades capitalistas desenvolvidas, sendo o impacto político diferenciado conforme nação ou conjuntura.

Para as pesquisas em nosso país, consideramos a necessidade de absorver os elemen- 
tos descritos pelo fato do Brasil inserir-se na rede internacional de trocas do capitalismo e não estar à margem de tendências observadas nos países centrais. Isto estimula a recusa a conceitos de representação de interesses exclusivamente baseados no patrimonialismo, no corporativismo autoritário ou na luta direta entre as classes sociais. O estudo da organização dos interesses socialmente colocados passa pela observação de elementos detectados em sociedades com um padrão de acumulação capitalista mais intenso, para que se apreenda as singularidades nacionais, regionais ou setoriais.

\section{PONTOS PARA O ESTUDO DE POLÍTICAS SOCIAIS NO BRASIL}

1. As análises sobre políticas sociais no Brasil, e, em nosso caso, sobre as políticas de saúde, podem se beneficiar com a incorporação de elementos presentes nos estudos sobre o neocorporativismo. As relações corporativas tradicionais são bem reconhecidas em nosso país, assim como o caráter autoritário predominante nas relações entre o Estado e a representação funcional. O conceito de neocorporativismo, em que pese os enfoques diferenciados, pressupõe elementos adicionais tais como troca, espaços para negociação e organização funcional dos diferentes atores coletivos. Estes aspectos não são absorvidos pela conceituação tradicional de corporativismo. Tais elementos encontram-se presentes e em desenvolvimento na área da saúde em nosso país, principalmente se tomamos como referência as relações governamentais (nos vários níveis), as aspirações participativas e co-gestionárias presentes nas pautas das associações de interesses dos trabalhadores da área, e as definições de caráter democratizante presentes na elaboração do Sistema Único de Saúde (gestão dos recursos e serviços compartilhada entre Estado, trabalhadores de saúde e usuários).

2. Os arranjos neocorporativos não constituem elementos paradigmáticos em Ciência Política, mas estruturas que vão se desenvolvendo na sociedade capitalista no sentido de dar conta da redução do conflito global da sociedade e da resolução localizada de problemas que se colocam para o Estado e para os atores sociais coletivos.

3. Os textos de Offe ganharam destaque recente em nosso país, podendo sua importância ser medida através das constantes referências à sua obra observadas em trabalhos de autores nacionais na área de pesquisa social, inclusive na saúde. Ao colocarmos em destaque os seus pontos de vista, vemo-nos obrigados a discernir quais conceitos têm aplicação mais direta ao nosso campo de trabalho, haja vista a enorme diferença entre as bases empíricas.

4. Inicialmente, é necessário esclarecer algumas das diferenças centrais entre o caso brasileiro e o dos países de capitalismo desenvolvido (especialmente a Europa). Os itens mais significativos, afora as próprias dimensões em termos de produção econômica, poderiam, apenas como resumo, ser colocados da seguinte maneira:

- Não houve, no Brasil, a construção de um Estado de Bem-Estar que pudesse servir de base para ações de superação do mesmo e nem de análises comparadas de políticas sociais dentro de um contexto assistencialista geral. Nossos estudos devem, assim, ser colocados de um modo diferente - ou seja, são partes de conjunturas e processos de desenvolvimento de um Estado não voltado para a proteção social global;

- Os agentes societários, no Brasil, não experimentaram um processo histórico de organização de modo a provocar impactos duradouros na organização do Estado, e mesmo o movimento sindical (o exemplo mais sólido de práticas de representação de interesses) só mais recentemente dá passos rumo a uma influência nas políticas de Estado que possam levar a comparações com os arranjos neocorporativos de outros países (na verdade, o sindicalismo brasileiro passou a maior parte de sua história dentro de padrões corporativos do tipo dirigista, implantado desde a década de 30, suplantando as formas de sindicalismo independente só mais recentemente retomadas);

- No Brasil, pela sua própria formação social, os conflitos extra-institucionais são muito mais frequientes e violentos do que no quadro europeu e, conforme a conjuntura, chegaram 
a ocupar o primeiro plano no padrão de conflitos no país (conflitos de terra, movimentos de resistência aos regimes militares, greves" selvagens", etc.);

- O Estado brasileiro não pode ser interpretado apenas com o instrumental de Offe, pois o acesso burguês às políticas e à burocracia tem, além dos elementos assinalados, componentes patrimonialistas e autoritários, que colocam distante a pura e simples racionalidade de "viabilização da forma-mercadoria";

- Por fim, dentre outras diferenças, a formação partidária brasileira está longe de apresentar um quadro consistente de representação territorial e ideológica, mesmo com o advento mais recente do Partido dos Trabalhadores, com a legalização dos partidos comunistas e com a reimplantação de partidos (em geral conservadores) de bases regionais;

5. Por outro lado, uma vez tomados os cuidados assinalados, os estudos de Offe contribuem de modo muito rico para o entendimento das políticas públicas no Brasil e das suas relações com as formas societárias de representação de interesses. Um ponto que chama a atenção, por exemplo, é o fato do discurso de esquerda e das demandas de diversos setores organizados da sociedade estarem centrados na chamada "participação popular" perante as políticas públicas, o que torna atual a discussão acerca das formas de arranjos neocorporativos se estabelecerem no Brasil pela via do discurso de esquerda (principalmente se agregarmos exemplos sobre as práticas sindicais recentes em serviços públicos). Com a crescente reorganização do movimento sindical em níveis nacionais; Central Única dos Trabalhadores (CUT), Confederação Geral dos Trabalhadores (CGTs), Força Sindical; e dos demais movimentos sociais (sem-terra, comunitários, ambientalistas, etc.), a questão da introdução de arranjos corporativos na mediação de conflitos em bases diferentes da tradição corporativista autoritária entra na ordem do dia, freqüentando o próprio noticiário jornalístico (pacto social, comissões paritárias, "sindicalismo de resultados", etc.), estando ainda em aberto qual será o padrão dominante de resolução de conflitos no país (ou mesmo se tal se dará por mecanismos extra-institucionais).
6. Constata-se, com maior nitidez, os impactos de atitudes de representação organizada de interesses sobre a organização de políticas sociais, como pode ser verificado através de diversos exemplos - as tentativas, no momento discursivas, de articulação de pactos sociais no Brasil envolvendo governo, centrais sindicais e associações empresariais (governo e "organizações-pico"); a organização de câmaras setoriais para enfrentar políticas de preços (até o momento sem a participação dos sindicatos de trabalhadores); os acordos de correntes sindicais com o Ministério do Trabalho (embora mais característicos de arranjos corporativos tradicionais); e a atuação fortemente organizada dos diferentes setores da sociedade junto à Assembléia Nacional Constituinte - um processo que pode ser cosiderado como um pacto social nacional de transição política.

7. No setor saúde, o processo experimentado na Assembléia Nacional Constituinte e na elaboração e aprovação dos princípios gerais do Sistema Único de Saúde é um exemplo da importância desfrutada por propostas participativas e co-gestionárias junto aos partidos de esquerda e sindicatos. Neste modelo, o Estado surge como estendendo "um tapete" (que seriam as políticas públicas) que funciona como espaço de conflitos e negociações entre os diferentes atores sociais coletivos. Seria, deste modo, o Sistema Único de Saúde um exemplo de arranjo neocorporativo, apesar da exclusão do setor privado de seu espaço decisório, estabelecida pelos seus proponentes. Acordos de condução de políticas a níveis locais, especialmente no âmbito dos municípios, onde sobressaem-se as relações entre governos e trabalhadores de saúde, e mesmo de associações comunitárias, compõem um padrão setorial de arranjos neocorporativos que não podem ser também esquecidos na pesquisa social.

8. O enfraquecimento do padrão de Estado assistencialista na Europa e nos Estados Unidos cria, no Brasil, um ambiente favorável ao ataque ideológico neoconservador às políticas estatais, enfraquecendo aqui este modelo de distribuição de "bens públicos" e interferindo na execução de diversas políticas (habitacional, educacional, sanitária). O enfraquecimento, aqui também notado, no modelo de correção das injustiças sociais via políticas de Estado atinge 
a própria esquerda brasileira (Partido dos Trabalhadores (PT), sociais-democratas, PCs, etc.), cujas políticas têm sido nitidamente vinculadas a dois padrões: às políticas redistributivas do Estado e ao estímulo participativo dos setores sociais não detentores de capitais - conferindo aos projetos da esquerda no Brasil padrões neocorporativos subordinados à expansão da burocracia estatal.

9. Nota se no discurso neoconservador brasileiro uma tendência à transposição global dos diagnósticos e das soluções observadas nos países centrais, sem a elaboração adequada de um projeto adaptado às bases nacionais. Porém, o conhecimento dos determinantes desta "onda conservadora" é crucial, pois torna-se provável a colocação destes princípios nos projetos de atuação dos diversos ministérios envolvidos com as principais políticas sociais (como já foi notado no Ministério da Saúde e nas políticas científicas, por exemplo).

10. O destaque dado por Offe aos elementos individuais presentes na ação coletiva não serve apenas para assinalar os limites de explicações fundadas exclusivamente em modelos neocorporativos. Ele também assinala a importância dos estudos levarem em conta os cálculos racionais na ação coletiva, não como um enfoque racionalista (onde o desejo do indivíduo fosse cerceado pelas estruturas), mas enfatizando a presença de estruturas de oportunidades nas quais os atores coletivos e individuais atuam. As políticas sociais em saúde conformam um terreno de atuação e conflitos a ser estudado sem se ocultar a forte participação do Estado (o que enfraquece os modelos pluralistas de análise), sem se submeter ao paradigma da luta de classes no capitalismo (o que enfraquece uma leitura conservadora do marxismo), e sem subestimar os mecanismos pelos quais os interesses individuais se coletivizam em nossa sociedade.

12. Os itens aqui descritos conformam um projeto em desenvolvimento que se constitui em uma tendência que pode ou não se fortalecer, conforme fatores conjunturais. Um destes fatores seria, por exemplo, um acesso mais significativo da esquerda social-democrata a níveis cada vez mais elevados de decisões políticas do Estado. A isto se contrapõem outras tendências, como o caráter burocrático e autori- tário do Estado Brasileiro, restringindo o acesso a seus níveis centrais de decisão política por canais societários.

13. A relevância do que foi aqui discutido para o estudo ao qual nos propomos, como desdobramento desta dissertação, está em que o processo de trabalho e a produção de serviços em saúde sofrem impactos das atitudes individuais e organizadas dos profissionais do setor, especialmente dos médicos. A consolidadação de um padrão negociado de redução de conflitos e de gestão de políticas sociais evidencia mais ainda os mecanismos de defesa de interesses das categorias profissionais da saúde, especialmente dos médicos. As atitudes individuais e coletivas destes profissionais (e a forma como tenderão a operar com os padrões cada vez mais negociados de atuação profissional) são cruciais para o resultado destas políticas e para o próprio processo de trabalho em saúde. Itens como jornada de trabalho efetiva dos médicos, tempo de consulta, consumo de equipamentos e medicamentos, controle de qualidade dos serviços e supervisão técnica, democratização dos prontuários médicos, captação individual de clientela, entre outros, são elementos de forte impacto no produto final das políticas sociais no setor (não apenas nos serviços públicos, mas, obviamente, no setor privado) com os quais governos (federal ou locais), usuários e profissionais do setor se defrontam e nos quais arranjos de resolução de conflitos tendem cada vez mais a se impor.

\section{RESUMO}

\section{RIBEIRO, J. M. A rranjos N eocorporativos e D efesa de Interesses do M édicos. Cad.} Saúde Públ., Rio de Janeiro, 9 (1): 05-20, jan/mar, 1993.

No Brasil, o modelo sindical formado a partir do corporativismo autoritário instituído na década de 30 sofre transformações com o fim do ciclo militar inaugurado em 1964. Com a redemocratização, o movimento sindical passou a conviver com a representação plural de interesses, o que se refletiu no sindicalismo médico a partir de 1977. O arranjo político decorrente da Constituinte de 1988 consagrou, 
no caso da saúde, formas pluripartites de gestão da política pública. Propomos uma discussão conceitual acerca dos arranjos neocorporativos, característicos das experiências sociais européias, e sobre a sua relevância para a compreensão da política pública em saúde no contexto da chamada Reforma Sanitária.

Palavras-Chave: Arranjos Neocorporativos; Médicos; Políticas de Saúde

\section{REFERÊNCIAS BIBLIOGRÁFICAS}

BERL INGUER, G., 1988. U ma reforma para a saúde. In: R eforma Sanitária - I tália e B rasil (G. Berlinguer, org.), pp. 1-106, São Paulo: Hucitec-Cebes.

BJ ORK M AN, J. W., 1988. Comparative Health Policies: A World of D ifference. Relatório apresentado ao XIV Congresso da Associação Internacional de Ciências Políticas, Washington, D. C.. (Mimeo.)

CAM POS, G. W. S., 1988a. Os M édicos e a Política deS aúde. São Paulo: H ucitec. , 1988b. A Reforma Sanitária necessária. In: R eforma Sanitária - Itália e B rasil (G. Berlinguer, org.), pp. 179-194, São Paulo: H ucitec-Cebes. , 1991. A S aúde Pública ea D efesa da Vida.São Paulo: H ucitec.

CONFERÊNCIA NACIONAL DE SAÚDE VII, 1980. Anais, Brasília-DF.

CONFERÊNCIA NACIONAL DE SAÚDE VIII, 1986. Anais, Brasília-D F.

COST A, N. R., 1989. Transição e movimentos sociais: contribuição ao debate da R eforma Sanitária. In: Demandas Populares, Políticas Públicas e S aúde (N. R. da Costa, org.), pp. 4565, Vol. I, Petrópolis: Vozes-Abrasco.

D ON NÂN GEL O, M. C. F.; PEREIRA, L., 1979. Saúde e S ociedade. 2ª ed., São Paulo: Livraria D uas Cidades.

ERICK SON, K. P., 1979. Sindicalismo no P rocesso Políticodo B rasil. São Paulo: Brasiliense.

ESCORE L, S., 1987. R eviravolta na Saúde: O rigem eArticulação do M ovimento S anitário. Tese de M estrado, Rio de J aneiro: Escola $\mathrm{N}$ acional de SaúdePública.

FAVARET-FIL H O, P. \& OL IVEIRA, P. J., 1989. A U niversalização Excludente- Reflexões Sobre as Tendências do Sistema de Saúde. Texto para discus-são no216, I.E .I./UFRJ . (M imeo.)
GRAM SCI, A., 1978. Concepção Dialética da H istória. 2a ed., Rio de Janeiro: Civilização Brasileira.

,1968. Os Intelectuaisea O rganização da C ultura. Rio deJ aneiro: Civilização Brasileira.

IL LICH, I., 1975. A Expropriação da SaúdeNêmesis da M edicina. 2ª ed., Rio de Janeiro: Nova F ronteira.

INCISA, L , 1986. Corporativismo. In: D icionário de Política (N. Bobbio, org.), 2a ed, pp. 287-291, Brasília: EditoraUniversidade de Brasília.

KING , D., 1988. 0 Estado e as estruturas de bem-estarem democracias industriais avançadas. N ovos E studos/Cebrap, 22: 53-76.

KONDER, L . A, 1988. A D errota da D ialética - A $R$ ecepção das I déias de $M$ arx no $B$ rasil até 0 Começo dos Anos Trinta. Rio de J aneiro: Campus.

LEN IN, V. I., 1973. Q ue H acer? - Problemas Candentes de $\mathrm{N}$ uestro $\mathrm{M}$ ovimiento. $4^{\mathrm{a}}$ ed., Buenos Aires: Editorial Ateneo.

O'D ON NEL , G ., 1976. Sobre o corporativismo e a questão do Estado. C adernos do D epartamento de Ciência Política da Faculdade de Filsofia e Ciências $\mathrm{H}$ umanas da $\mathrm{U}$ niversidade $\mathrm{F}$ ederal de M inasGerais, 3: 1-53

, 1988. Transições, continuidades e alguns paradoxos. In: A D emocracia no B rasil Dilemas e Perspectivas (F. W. Reis, org.), pp. 41-71,São Paulo: Vértice/Editora Revista dosTribunais.

OFFE,C ., 1989a. A atribuição de status público aos grupos de interesse. In: Capitalismo D esorganizado (C. Offe, org.), pp. 223-268, São Paulo: Brasiliense. , 1989b. A democracia contra o Estado do Bem Estar. In: C apitalismo D esorganizado (C. Offe, org.), pp. 269-317, São Paulo: Brasiliense.

, 1989c. 0 crescimento do setor de serviços. In: Capitalismo D esorganizado (C. Offe, org.), pp. 131-165, São Paulo: B rasiliense. ,1984. Reflections on the welfare state and the future of socialism - an interview. In: Contradictions of the Welfare State (C. Offe, org.), pp. 252-299, Cambridge: MIT Press.

, 1983. Societal Pre conditions of Corporatism and some $C$ urrent Dilemmas of Democratic Theory. South Bend, Indiana: Universidade de N otre D ame. (M imeo.)

OFFE, C. \& RONGE, V., 1987. Teses sobre a fundamentação do conceito de "Estado capital ista" e sobre a pesquisa política de orientação 
materialista. In: P roblemas E struturais do E stado Capitalista (C. Offe, org.), pp. 122-139, Rio de Janeiro: Tempo Brasileiro.

OL IVEIRA, J . A., 1989. Reformas e reformismos: para uma teoria política da Reforma Sanitária (ou reflexões sobrea R eforma Sanitária de uma perspectiva popular). In: D emandaspopulares, $\mathrm{Po}$ líticas Públicas e Saúde ( N. R. da Costa, org.), pp. 13-44, Vol. I, Petrópolis: Vozes-A brasco.

PANIT CH, L ., 1981. Os sindicatos e o Estado no capitalismo avançado. R evista deC ultura ePolítica, 5/6: 81-104.

PRZEWORSKI, A., 1989. C apitalismo eS ocial-Democracia.São Paulo: Companhia das L etras.

SCHMIT TER, P. C., 1974. Still the century of corporatism?. R eview of Politics, 36: 85-131.
SCHRAIBER, L. B., 1988. M edicina e Incorporação de Tecnologia: as Transformações $H$ istóricas da Autonomia Profissional dos M édicos em São Paulo. Tese de D outorado, São Paulo: Universidade deSão Paulo.

SCH WART ZM AN, S., 1988. B ases do Autoritarismo B rasileiro. 3ed., Rio deJ aneiro: Campus.

TEIXEIRA, S. M. F., 1988. 0 dilema da Reforma Sanitária. In: R eforma Sanitária - Itália e B rasil (G. Berlinguer, org.), pp. 195-207, São Paulo: H ucitec-Cebes.

VIAN N A, L. W., 1976. Liberalismo e Sindicato no Brasil.RiodeJaneiro: PazeTerra.

WALL ERST EIN , M ., 1989. A centralização sindical edependências face ao comércio: as origens do corporativismo democrático. $D$ ados/R evista de CiênciasS ociais/l uperj, 32: 42-73. 